This item was submitted to Loughborough's Research Repository by the author.

Items in Figshare are protected by copyright, with all rights reserved, unless otherwise indicated.

\title{
Plasma-assisted pre-treatment of lignocellulosic biomass for anaerobic digestion
}

PLEASE CITE THE PUBLISHED VERSION

https://doi.org/10.1016/j.fbp.2020.09.005

PUBLISHER

Elsevier

VERSION

AM (Accepted Manuscript)

\section{PUBLISHER STATEMENT}

This paper was accepted for publication in the journal Food and Bioproducts Processing and the definitive published version is available at https://doi.org/10.1016/j.fbp.2020.09.005.

LICENCE

CC BY-NC-ND 4.0

\section{REPOSITORY RECORD}

Wright, Alexander, Andrew Rollinson, Dipti Yadav, Szymon Lisowski, Felipe Iza, Richard Holdich, Tanja Radu, and Hemaka Bandulasena. 2020. "Plasma-assisted Pre-treatment of Lignocellulosic Biomass for Anaerobic Digestion”. Loughborough University. https://hdl.handle.net/2134/12932822.v1. 


\title{
Plasma-assisted Pre-treatment of Lignocellulosic Biomass for Anaerobic Digestion
}

\author{
Alexander Wright 1, Andrew Rollinson 2, Dipti Yadav 2, Szymon Lisowski ${ }^{1}$, Felipe Iza ${ }^{3}$, Richard \\ Holdich ${ }^{1}$, Tanja Radu ${ }^{2 *}$ and H.C. Hemaka Bandulasena ${ }^{1 *}$ \\ 1 Department of Chemical Engineering, Loughborough University, Loughborough, Leicestershire, LE11 \\ 3TU, United Kingdom \\ 2 School of Architecture, Building and Civil Engineering, Loughborough University, Loughborough, \\ Leicestershire, LE11 3TU, United Kingdom \\ 3 Wolfson School of Mechanical, Electrical and Manufacturing Engineering, Loughborough University, \\ Loughborough, Leicestershire, LE11 3TU, United Kingdom \\ * Correspondence: T.Radu@lboro.ac.uk (T.R.); $\underline{\text { H.C.H.Bandulasena@lboro.ac.uk (H.B.) }}$
}

\section{H I G H L I G H T S}

- A novel microbubble-enhanced plasma reactor for pre-treatment of AD feedstocks

- Plasma pre-treatment led to $18 \%$ increase in biogas production from batch experiments

- Continuously fed AD reactors showed no improvement in biogas yields from pre-treatment

\begin{abstract}
The conversion of industrial crops to energy has received significant attention recently as a means to reduce carbon emissions and meeting the renewable energy targets. Samples of whole crop maize (Zea mays L.) were pre-treated in tap water using a novel microbubble-enhanced dielectric barrier discharge (DBD) plasma reactor that generates highly reactive species in situ and distribute them using microbubbles. The pre-treated maize was then used as feedstock in batch and continuously-fed mesophilic continuously-stirred anaerobic digesters (AD). Half of the pre-treated samples were washed in deionized water prior to feeding to assess the effect of possible inhibitory by-products generated during pre-treatment. In batch AD experiments, DBD-plasma pre-treated and washed maize produced $18 \%$ greater biogas production in comparison to untreated raw samples, and unwashed samples produced $29 \%$ lower biogas than the untreated samples. These results suggest the production of inhibitors to the AD process, but biogas production can be enhanced by removing these inhibiting compounds. Continuously-fed AD reactors exhibited no noticeable change in biogas output between raw and plasma-treated maize. For AD reactors operating in batch, or with a relatively long residence time and fed with high lignocellulose feedstocks, plasma-microbubble pre-treatment could enhance biogas output and process efficiency.
\end{abstract}

Keywords: Biogas, Dielectric barrier discharge plasma, Maize, Methane, Microbubbles

\section{Introduction}

Anaerobic digestion (AD) is a bio-degradation process actuated on organic matter under anaerobic conditions. It is a widely used for processing sewage sludge generated from wastewater treatment plants, resulting in both volume reduction and stabilisation along with the simultaneous production of biogas (a mixture of methane and carbon dioxide in an approximate volumetric ratio of 60:40, with trace amounts of other species). The AD process has also been deployed as a stand-alone system for biogas production; an application which has been subject to greater focus in the last few decades as 
society seeks to divert organic waste from landfills and find more secure and sustainable energy sources (Abbasi at al., 2012). This has extended the use of both waste and dedicated energy crops as feedstock. In Europe, one of the most popular industrial cultivars for AD is Maize (Zea mays L.- in further text referred to as "maize") which is attractive due to its fast growth rate allowing two crops per season, and because whole plants can be utilised both 'green' and ensiled (Negri at al., 2014 a, b). It is also relatively rich in both cellulose and hemicellulose and contains complex aromatic polymer lignin. For example, Li et al. (2009) reported cellulose, hemicellulose and lignin contents of $37.5 \%, 30 \%$ and $8.4 \%$ respectively for corn stover. Cellulose and hemicellulose are readily biodegradable once links with non-structural carbohydrates and lignin has been removed by pre-treatment, so that high methane yields can be produced in the range of ca. 10,000 $\mathrm{m}^{3}$ ha-1 $^{-1}$ (Brenner et al., 2012). Lignin is mostly recalcitrant to $\mathrm{AD}$, thus representing a loss in process efficiency.

Various methods have been implemented to target and break down the lignin polymers in plant structure with the aim of improving AD efficiency. Many of these methods derive from the paper industry and are broadly categorised as thermal, microwave, mechanical, chemical, and wet oxidation techniques (Carlsson et al., 2012). Menardo et al. (2012) reported $80 \%$ improvement in methane yield by mechanical pre-treatment and $60 \%$ by thermal pre-treatment for wheat barley and straw. However, for maize stalks they concluded that mechanical pre-treatment and (decrease in particle size) resulted in no significant improvement in methane recovery in anaerobic digestion. Chemical treatments are the most common, aiming to accelerate AD hydrolysis by soaking the biomass in acid or alkaline, solutions depending on the feedstock type (Fernandes et al., 2009). While often effective, problems are created when the material is subsequently used as AD feedstock due to the extremes in $\mathrm{pH}$ and the inhibitory effect of pre-treatment residues and refractory by-products (Koyama et al., 2015, Koyama et al., 2017).

Ozone has been suggested as a better chemical pre-treatment method, though only recently has its use on lignocellulosic biomass been explored (Carlsson et al., 2012). It does not produce the extremes of $\mathrm{pH}$ and is alleged to minimize the production of inhibitory by-products (García-Cubero et al., 2009). There is, however, contradictory literature on the production and retention of refractory residues (Panneerselvam et al., 2013). Other researchers have dismissed ozone pre-treatment as being too costly (Kumar et al., 2009). Elsewhere there have been reports of lower efficiency with ozone in comparison to thermal, or ultrasonic, treatment (Bougrier et al., 2006). Currently, dielectric barrier discharge (DBD) plasma is often used to produce ozone efficiently for industrial applications (Vezzu et al., 2009). Heiske et al. (2013) reported $45 \%$ improvement in methane yield for their plasma-assisted pre-treatment of lignocellulosic feedstock (wheat straw) prior to anaerobic digestion.

This investigation builds on previous research using a novel plasma-microbubble reactor to produce a DBD plasma at the gas-liquid interface of the microbubble generation sites (Wright et al., 2018 a, b, Wright et al., 2019). Ozone and other highly reactive species produced by plasma have high oxidation potential and are well known to break the carbon-carbon double bonds in lignocellulosic biomass (Wright et al., 2018 a). Even though ozonolysis, oxidative cleavage of unsaturated compounds with ozone dissolved in liquids, has been applied to biomass pre-treatment, research on combined effect of Reactive Oxygen and Nitrogen Species (RONS) produced by plasma for AD pretreatment is limited. The main objective of this study was to test whether highly reactive species, facilitated by the use of an in-situ microbubble contactor design and not just ozone, generated by a DBD plasma reactor could be used to effectively pre-treat maize prior its use as an AD feedstock. A regime of washing was applied to half the pre-treated samples fed into the AD reactors to test for the presence of possible plasma-derived inhibitors to AD treatment. 


\section{Materials and Methods}

\subsection{Feedstock Preparation and Characterisation}

Maize was obtained from Stoke Bardoloph, Severn Trent Water, Nottingham, UK in the form of whole plants. It had been grown on land previously used for the disposal of sewage sludge and therefore deemed unsuitable for agriculture. The maize was harvested in the autumn, chopped to a ca. $6 \mathrm{~mm}$ cut, and then stored on-site in clamps for between 12 to 18 months. Random samples were collected from these clamps and dried at $105^{\circ} \mathrm{C}$ in a laboratory oven for two hours. They were then shredded to 1-2 mm using a cutting mill (Pulverisette 15, Fritsch $\mathrm{GmbH}$ ). The prepared maize was characterised for total solids (TS) and volatile solids (VS) using standard methods (APHA, 1999). Characterisation of the lignocellulosic composition was outsourced to Celignis Analytical, ROI, using an analytical protocol as per (Sluiter et al., 2005 a, b, Sluiter et al., 2008).

\subsection{Pre-treatment}

\subsubsection{DBD Plasma-Microbubble Reactor}

Design details and characterization of the plasma-microbubble reactor used in this study are described elsewhere (Wright et al., 2018 a, b; Wright et al., 2019). The reactor consisted of two sections: the plasma module (lower section) and the reaction tank (upper section) separated by a perforated nickel membrane (Figure 1). Air was supplied to the plasma chamber at 1.5 SLPM via a mass flow controller (PR4000B, MKS Inc). The porous nickel membrane acted as both the ground electrode for the plasma discharge and the sparger for microbubble production. The microbubbles produced had a mean diameter of ca. $550 \mu \mathrm{m}$ (bubble diameter range $200 \mu \mathrm{m}$ to $1 \mathrm{~mm}$ ) (Wright at al., 2019). The reaction tank had an internal diameter of $152 \mathrm{~mm}$ and height of $200 \mathrm{~mm}$. A separate study was conducted to evaluate the design and characterization of this plasma-microbubble reactor (Wright at al., 2019). Optimal operating frequency was selected based on uniformity of the plasma discharge across the bubble generating membrane and the power consumption. The duty cycle (fraction of time plasma was kept on in a cycle) was optimized for RONS generation (Wright et al., 2018). A full-bridge resonant power supply operating at $21 \mathrm{kHz}$ with a sinusoidal voltage of $16 \mathrm{kV}_{\mathrm{pp}}$ was modulated at $45 \%$ duty cycle (equivalent to a power draw of $18.6 \mathrm{~W}$ ) for this study.

In this study, treatment media was $390 \mathrm{ml}$ tap water at $\mathrm{pH}$ 7.4. To this was added $20 \mathrm{~g}$ of dried and shredded maize. DBD plasma treatment time was selected to be 2 hours based on the previous pre-treatment work carried out with this reactor (Wright et al., 2018). As a control, a further maize sample was treated within the rector in tap water but without power to the plasma module to determine the effect of the bubbles. 


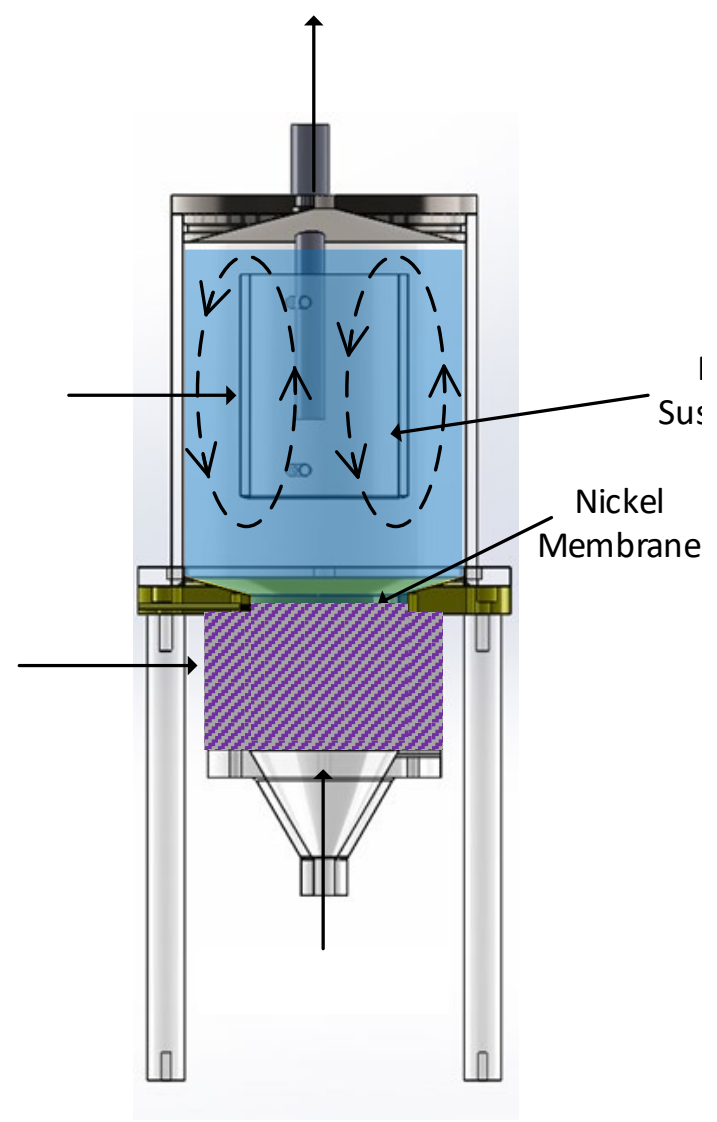

Figure 1. Schematic diagram of the DBD plasma-microbubble reactor used for pre-treatment of maize

\subsubsection{Scanning Electron Microscopy}

All DBD plasma-treated and raw maize samples were analysed by Scanning Electron Microscopy (SEM) following sputter coating (SC7640, Quorum Tecnologies Ltd) with gold/palladium for $180 \mathrm{~s}$ at $25 \mathrm{~mA}$ to provide a $5-10 \mathrm{~nm}$ thick conductive layer. Analyses were completed using a Leo (Zeiss) 1530-VP FEGSEM. Imaging was carried out at $20 \mathrm{kV}$ accelerating voltage with an aperture of $30 \mu \mathrm{m}$ and observed in standard secondary electron mode.

\subsubsection{Attenuated Total Reflection - Fourier-transformed Infrared Spectroscopy (ATR-FTIR)}

All samples were first ground to a homogenous powder. They were then placed in sample holders (GS10800-x, Quest Ltd) and analysed using an ATR-FTIR by IRAffinity-1, Schimadzu Inc. A total of 64 scans were taken with a resolution of $4 \mathrm{~cm}^{-1}$, between the range of 400 to $4000 \mathrm{~cm}^{-1}$. A background scan was also taken prior to each analysis and deducted from the final result.

\subsection{Anaerobic Digestion}

\subsubsection{Feedstock Preparation}

Following DBD plasma pre-treatment, maize suspensions were fed to AD reactors in either unwashed or washed form. For preparation of the washed feed, samples were first separated from suspension by filtration using a Buchner funnel with Whatman Grade 413 filter paper (particle retention $5 \mu \mathrm{m}, \mathrm{VWR}$ ). They were then washed with de-ionised water and dried in an oven for 12 hours at $105^{\circ} \mathrm{C} .20 \mathrm{~g}$ of this dry material, collected from several pre-treatment batches, was then resuspended in $450 \mathrm{ml}$ of tap water. Unwashed liquid samples were neutralised with $1 \mathrm{M} \mathrm{NaOH}$ and 
the total volume was adjusted to $450 \mathrm{ml}$ by adding tap water. Neutralisation was necessary as $\mathrm{pH}$ of the suspension dropped to $\sim 4$ following pre-treatment due to reactive nitrogen species. For the control experiments, several maize samples were prepared by bubbling maize suspensions in the reactor for 2 hours with the plasma module turned off. These bubble-treated maize samples were then filtered, dried and resuspended in tap water prior to AD feeding. Sample quantity was standardised at $20 \mathrm{~g}$ TS for crop feed (irrespective of the sample pre-treatment i.e. raw, bubble-treated and both washed and unwashed plasma pre-treated maize) in $450 \mathrm{ml}$ of tap water for all the AD feeds. The VS content of the raw, unwashed and washed maize is $96.5 \%, 98.2 \%$ and $98.3 \%$ (fraction of TS) respectively. The resulting Organic Loading Rates (ORL) for these reactors were 2.14, 2.18, and $2.19 \mathrm{~g} \mathrm{VS} / 1$-day for raw maize, pre-treated unwashed and pre-treated washed feed, respectively. This was to attain comparability with the TS and VS of a control sample of $450 \mathrm{ml}$ sewage sludge (organic loading rate of $2.43 \mathrm{~g} \mathrm{VS} / \mathrm{l}$-day) and to better understand the effect of pre-treatment on a fixed amount of feedstock.

\subsubsection{Batch Experiments}

Biogas was produced using a methodology recommended by Strömberg et al. (2014). Experiments were repeated in triplicate for each sample set using an array of 11 continuously-stirred anaerobic digesters. Each reactor was subject to a $52 \mathrm{rpm}$ stirring intensity (through a top-mounted gearbox), while placed in an electrically heated water bath set at $38( \pm 2){ }^{\circ} \mathrm{C}$. The unit was part of a Biochemical Methane Potential (BMP) kit supplied by Anaero Technology, UK. The water bath had a sealed lid to contain heat and reduce evaporative losses, and reactors were made of opaque HDPE. Each reactor had an independent gas line that was diverted through a translucent communal waterfilled reservoir containing an array of individual pre-calibrated tipping bucket flow cells. Each individual flow cells was in turn connected to its own 51 Tedlar bag (by Essvial, US, part 1212-7000GD).

Prior to the experiment, all reactors were filled with $650 \mathrm{ml}$ of inoculum obtained from a functional AD reactor at a waste-water treatment plant (Wanlip, UK). Inoculum was collected two days prior to experimentation, then kept in covered and refrigerated conditions. Eighteen hours before the experiment it was acclimatised to room temperature.

Three inoculum-only reactors were used as a baseline primary control. Twelve additional reactors were used to assay (in triplicate) the following samples: raw, unwashed plasma treated, washed plasma treated, and bubble treated maize. In these, maize was fed in a ratio with respect to inoculum of $1: 4$ based on VS content. This equated to $3.85 \pm 0.1 \mathrm{~g}$ for raw and washed (dry solids), and $9.07 \pm 0.2 \mathrm{~g}$ for unwashed (filtered wet solids). The plasma treated samples were prepared 24 hours in advance and kept refrigerated in covered flasks, then acclimatised to room temperature before use as $\mathrm{AD}$ feed. The duration of the batch experiments was 35 days. During this time gas output data was logged onto a personal computer via an Arduino 2560 microcontroller. Microsoft Excel was used to correct the biogas production to a N.ml/gvs basis, following discounting of the average residual biogas from the three inoculum reactors. Biogas data was not corrected for water vapour. The Tedlar bags were evacuated on days 7, 14, and 35 using a handheld gas composition analyser (Gas Data GFM416, UK), which quantified percentage of $\mathrm{CH}_{4}, \mathrm{CO}_{2}$ and $\mathrm{O}_{2}$ in biogas, and $\mathrm{H}_{2} \mathrm{~S}$ in ppm.

\subsubsection{Continuous Feeding Experiments}

Four 10 litre capacity (9 litre working volume) AD reactors were constructed from borosilicate glass culture vessels (Fisher Scientific - 15507910). Each vessel was fitted with a compatible fouraperture borosilicate glass lid (Fisher Scientific - 11372025). Two gas outlet tubes were connected to 
the lid, with a manually operable sampling port in-line, and a Y-shaped connector which then fed both outlets into a calibrated gas flow meter by Ritter (MGC-1, V3.4 PMMA). A third aperture facilitated continuous stirring at a rate of $100 \mathrm{rpm}$ from an above mounted motor (Heidolph RZR 2102). The reactors were maintained at $37 \pm 2^{\circ} \mathrm{C}$ ambient.

All four AD reactors were commissioned using the above described inoculum and fed by sewage sludge (Wanlip AD plant, UK) for 15 consecutive days prior to the experiments. They were then each fed separately for the next 24 days with either: sewage sludge, untreated suspension, pre-treated unwashed suspension and pre-treated washed suspension. In all cases, the reactors were fed once a day from Monday to Friday, with no feeding at the weekends. Immediately prior to feeding, $450 \mathrm{ml}$ of digestate was removed for analysis through a $25 \mathrm{~mm}$ diameter glass-blown outlet at the reactor base. Following digestate removal, fresh feed was added via one of the openings on the top of the reactor using a plastic funnel. The hydraulic retention time (HRT) in reactors was maintained at 20 days.

Fresh digestate from the continuously-fed reactors was analysed three times per week, on alternate days (i.e. Monday, Wednesday and Friday). First it was centrifuged at 10,000 rpm for 15 minutes (Eppendorf 5804). From the supernatant, concentrations of ammonium nitrogen $\left(\mathrm{NH}_{4}-\mathrm{N}\right)$ and Volatile Fatty Acids (VFA) were determined by UV spectroscopy (Hach Lange DR 3900, Germany) using chemical kits LCK 303 and LCK 365 respectively. The Ripley method was used to determine the ratio of VFA: TA (Total Alkalinity) (Ripley et al., 1986), using $0.1 \mathrm{M} \mathrm{HCl}$ as the titrant. A Mettler Delta 340 was used to measure $\mathrm{pH}$.

\section{Results and Discussion}

\subsection{Maize Feedstock Characterisation and DBD Plasma Treatment}

Results of the feedstock characterization analyses, as per section 2.1. above, are shown in Table 1.

Table 1. Results of maize characterisation (mean \pm standard deviation).

\begin{tabular}{ccccccc}
\hline \multicolumn{2}{l}{ Lignocellulosic } & Charactisation $(\%$ dry & matter, $\mathbf{n}=\mathbf{3})$ & \multicolumn{4}{c}{ Proximate Analysis $(\mathbf{\%}, \mathbf{n}=\mathbf{2})$} \\
\hline Cellulose & Glucan & 15.3 & \pm 0.04 & Moisture & 2.2 & \pm 0.1 \\
& Xylan & 9.4 & \pm 0.05 & VS (\%TS) & 96.4 & \pm 0.2 \\
Hemicellulose & Mannan & 0.3 & \pm 0.00 & TS & 97.8 & \pm 0.1 \\
& Arabinan & 1.8 & \pm 0.03 & & & \\
& Galactan & 0.7 & \pm 0.01 & & & \\
& Rhamnan & 0.1 & \pm 0.00 & & & \\
Lignin & Klason & 9.1 & \pm 0.14 & & & \\
& Acid soluble & 1.9 & \pm 0.05 & & & \\
Starch & & 19.2 & \pm 0.10 & & & \\
Ash & & 4.3 & \pm 0.05 & & &
\end{tabular}

SEM Micrographs of the raw maize (Fig. 2 a,b) reveal an undamaged sub-surface. This contrasts with the vacuous and physically damaged morphology exhibited by the pre-treated samples (Fig. $2 c)$. It has been suggested that such features could aid microbial access to the centre of the fibres and therefore benefit AD (Travaini et al., 2016). 
A comparison of the FTIR spectra for both samples also provided evidence of disruption to chemical functionality following pre-treatment (Fig. 3). Here the reduction in peak intensities at 3300 $\mathrm{cm}^{-1}, 2890 \mathrm{~cm}^{-1}$ and $1030 \mathrm{~cm}^{-1}$ can be attributed to stretching and vibrations of O-H, C-H and C-O bonds, respectively (García-Rosales and Colín-Cruz, 2010, Raspolli Galletti et al., 2015). The spectral range from $1300 \leq \mathrm{cm}^{-1} \leq 1750$ is generally attributable to lignin, with aromatic skeletal vibrations, $\mathrm{C}=\mathrm{O}$ stretching (aromatic groups), and $\mathrm{CH}$ deformation vibrations appearing in this region (GarcíaRosales and Colín-Cruz, 2010, Souza-Correîa et al., 2013). Of particular note is the large change in peak height at $1430 \mathrm{~cm}^{-1}$ which has been identified as due to $\mathrm{CH}_{2}$ scissoring in glucan and known to be a marker of crystallinity, where reduction in peak height indicates reduction in the degree of crystallinity (Synytsya and Novak, 2014). However, this reduction is not in conjunction with an increase in the absorption peaks at $893 \mathrm{~cm}^{-1}$, wavelength which corresponds to amorphous regions in cellulose (Karimi and Taherzadeh, 2016). This is somewhat expected as ozone and other reactive species cleave glycosidic linkages in the cellulose structure and decompose into smaller molecules (Lemeune et al., 2004). Lateral order index (O'Connor et al., 1958) calculated for raw and pre-treated maize are 1.13 and 1.09 respectively, which confirms indiscriminate reduction of both crystalline and amorphous regions following pre-treatment.
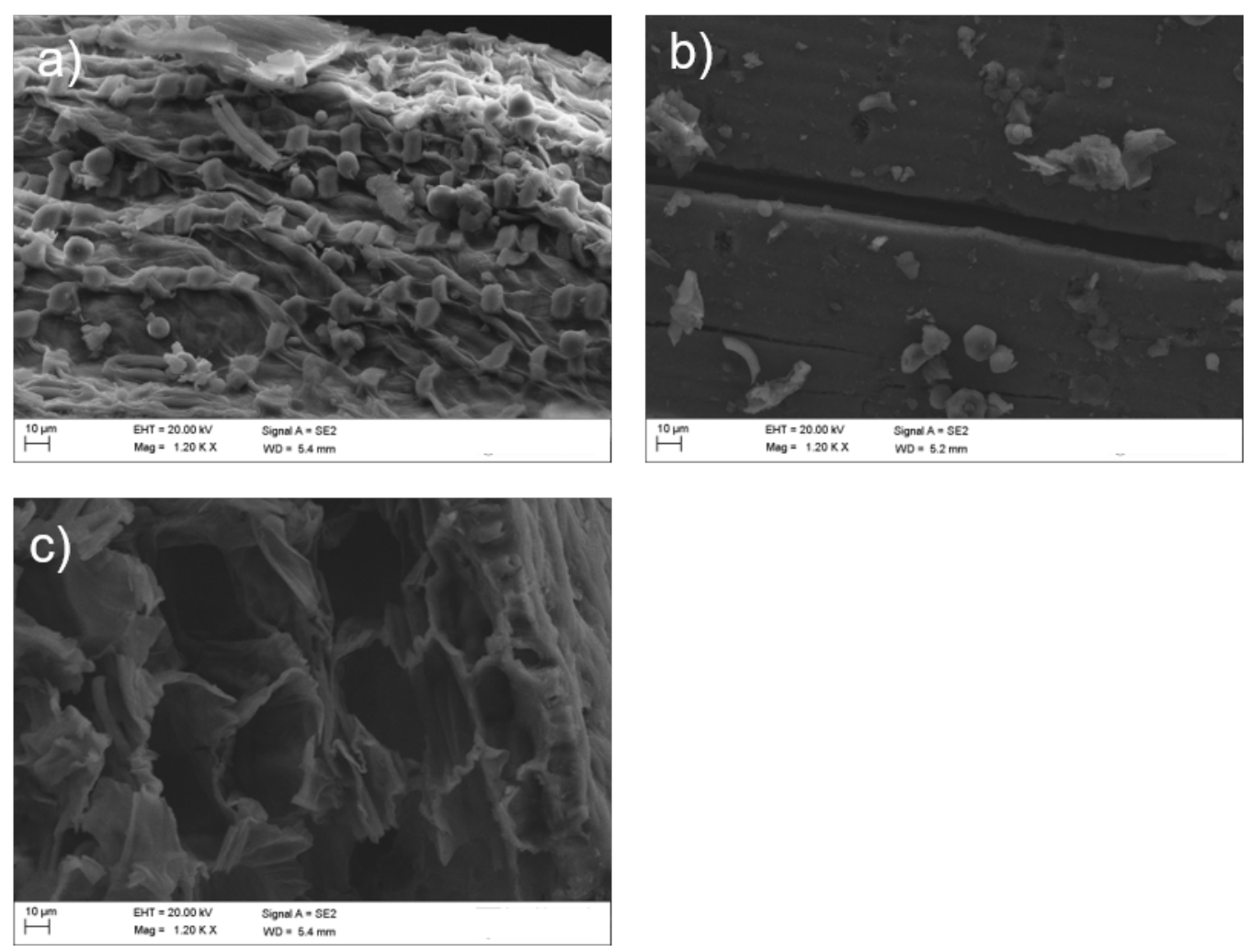

Figure 2. SEM images of dried and shredded maize samples: $(a, b)$ Raw maize - two different parts of the plant, (c) maize suspended in tap water pre-treated in the plasma-microbubble reactor. 


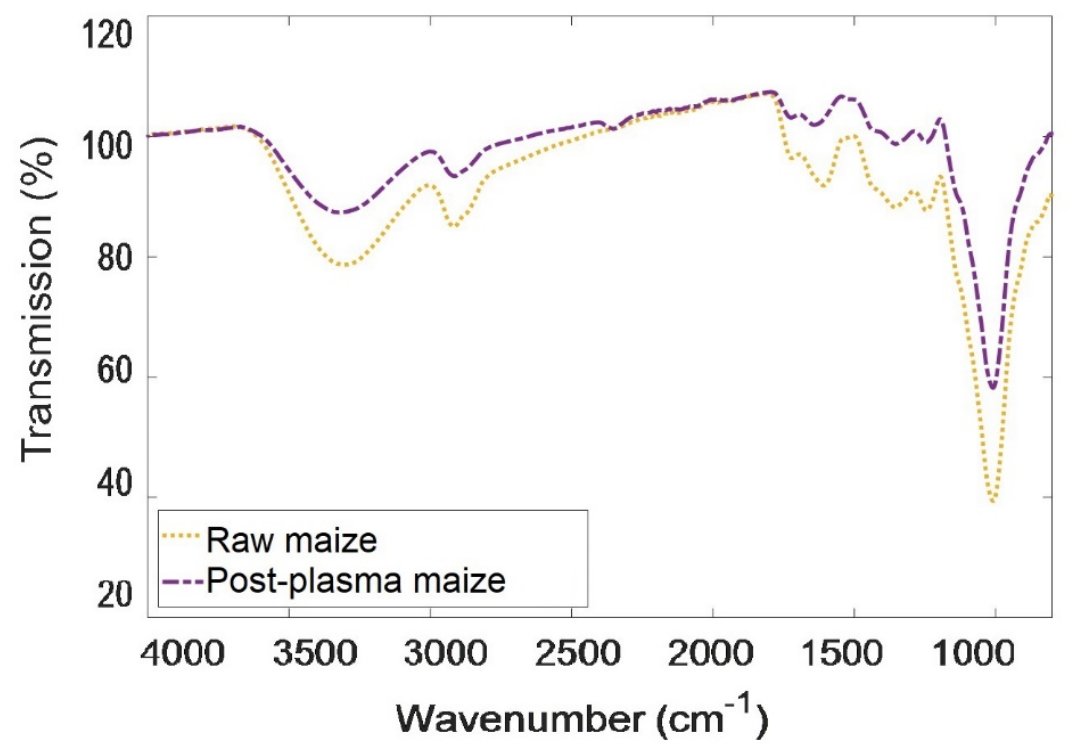

Figure 3. FTIR spectrum of raw and pre-treated maize samples.

\subsection{Anaerobic Digestion}

\subsubsection{Batch Experiments}

As shown in Figure 4, the cumulative biogas volume for all feeds show sharp initial increases followed by a decrease in production rate. Such decelerated exponential growth curves are the norm for batch process biogas production where the easily digestible material is metabolised rapidly leaving the more recalcitrant, slowly degradable materials (Moestedt et al., 2015). The final biogas volumes of the four sample sets were significantly different. Mean averages of washed DBD-plasma treated maize biogas production were $18 \%$ higher in comparison to untreated samples and unwashed samples produced $29 \%$ lower biogas than the untreated samples. From these results we infer the improved digestability of the DBD-plasma treated samples, but also the likely presence of soluble inhibitory compounds generated during the plasma pre-treatment process. The generation of inhibitory polymers has been described as a result of reactions during lignin breakdown by intense pre-treatment processing, especially in pre-treated samples not washed prior to hydrolysis (Panneerselvam, et al., 2013). Accumulated biogas production from the maize prepared by simply bubbling air through the suspension was the lowest of all samples tested. These bubble-treated maize samples were prepared for feeding by bubbling the maize suspension for $2 \mathrm{hr}$ (without plasma) followed by filtration, drying and resuspension of solids. It is highly likely that starch was washed away during this procedure. Therefore bubble-treated maize produced a low biogas yield compared to raw maize, where starch was available. The reactor fed with pre-treated and washed maize generated the most biogas even if starch had been removed in the washing step, as was indicated from the continuous feeding experiments (see section 3.2.2). Following these results an additional test was carried out to ascertain whether starch was removed from the solids during the washing step. For this, maize was washed prior to pre-treatment but the liquid used for washing was retained. This separated starch-rich liquid was later added to the plasma pre-treated and washed maize prior to AD feeding. A cumulative biogas volume of $813.42\left(\mathrm{Nml} / \mathrm{g}_{\mathrm{vs}}\right)$ was recorded after 35 days which was 4 times greater than that of the normal washed samples presented in Figure 4. This clearly highlights the importance of preserving the soluble fraction of the digestible material in the pre-treatment process, if washing is required post-treatment. 


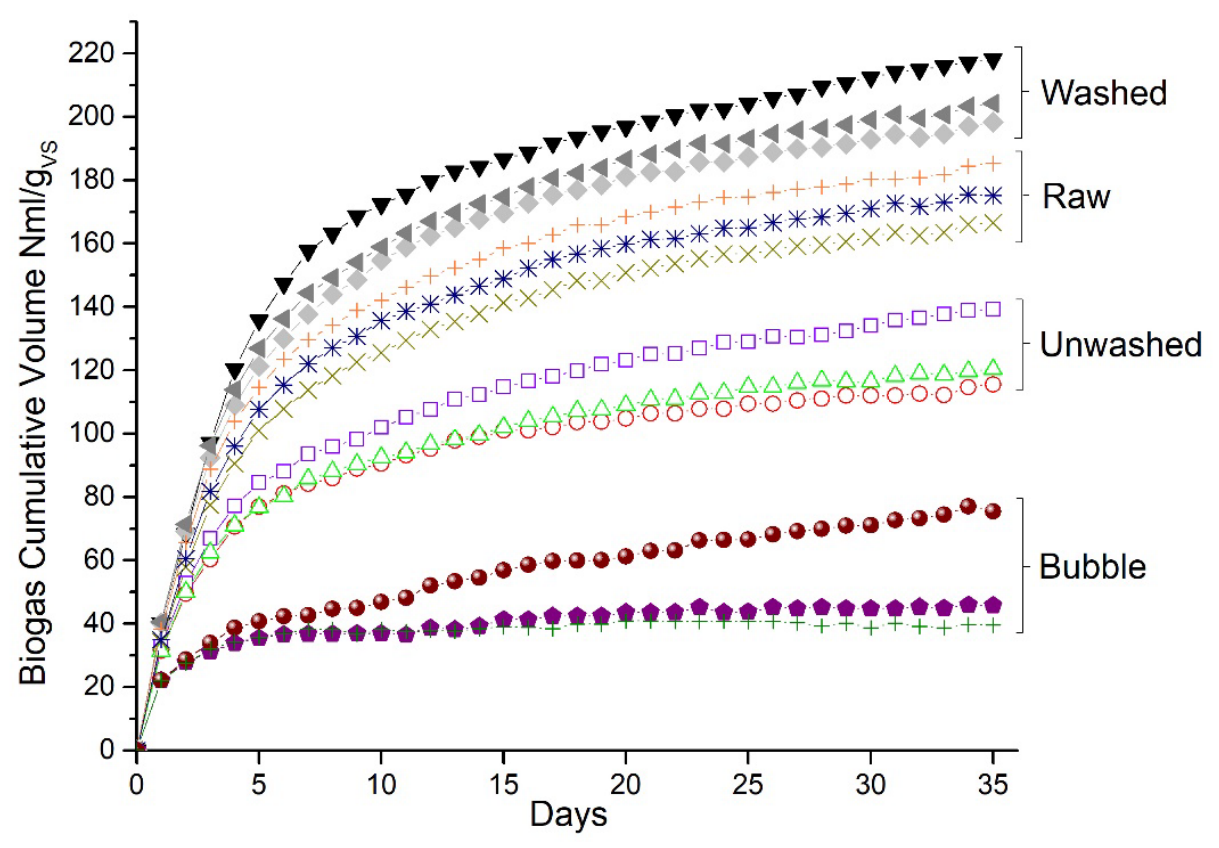

Figure 4. Cumulative biogas production from $\mathrm{AD}$ batch experiments using maize substrate.

There was no significant variation between the mean biogas $\mathrm{CH}_{4}$ and $\mathrm{CO}_{2}$ composition produced by the three batch reactors for the days 7, 14, and 35 (Table 2). All samples are at or slightly below the expected $\mathrm{CH}_{4}$ range of $54-56 \%$ for an optimised maize-fed AD reactor, as reported by Negri et al. (2014). In the case of pre-treatment by air bubbling (with no plasma), gas volumes were too low to accurately measure. Hydrogen sulphide $\left(\mathrm{H}_{2} \mathrm{~S}\right)$ was also measured and found only in the biogas from raw maize samples at concentrations of $15 \pm 10 \mathrm{ppm}$. One reason for this could be that the plasma treatment may have stripped the native sulphur. Alternatively, sulphur reducing bacteria (SRB) may have been inhibited by polymers created during the plasma treatment process. SRB are known to outcompete methanogens for acetate and hydrogen substrates, and their resulting $\mathrm{H}_{2} \mathrm{~S}$ is toxic to methanogenic archaea (Paulo et al., 2015). In addition, biogas commonly consists of other trace gases such as nitrogen, hydrogen, ammonia and water vapor (Rasi et al., 2007), but these gases were not measured in this study.

Table 2. The mean concentration (percentage) of methane and carbon dioxide in biogas from batch BMP experiments for samples accumulated for the days 7, 14, and 35 ( $n=3, \pm$ standard deviation).

\begin{tabular}{cccc}
\hline Sample & Unwashed & Washed & Raw \\
\hline $\mathrm{CH}_{4}(\%)$ & $53.6 \pm 2.8$ & $49.8 \pm 3.5$ & $49.6 \pm 6.4$ \\
$\mathrm{CO}_{2}(\%)$ & $16.7 \pm 0.4$ & $18.6 \pm 0.6$ & $19.0 \pm 1.8$ \\
\hline
\end{tabular}

\subsubsection{Continuous Feeding Experiments}

The cumulative biogas volume and methane volume produced from the AD reactors during the continuous feeding regime is shown in Figure 5. Methane composition for all reactors is shown in Figure 6. The reactor fed with sewage sludge produced the highest methane percentage (ca. $60 \%$ ). Sewage sludge contains more fat and protein, is relatively easier to digest and was the original substrate used for all reactors, prior to maize being introduced. On the other hand, pre-treated maize 
is unlikely to undergo complete hydrolysis during pre-treatment, hence unable to unlock the full potential of this feedstock. The complex nature of lignocellulosic plant polymers makes it less soluble and more difficult for microbial breakdown. Eastman and Ferguson (1981) stated that it is indeed the hydrolysis of particles, rather than soluble matter that is rate limiting in AD. Due to incomplete hydrolysis and low lipid content in maize, the methane output is expected to be reduced. This is seen with the $\mathrm{CH}_{4}$ percentage dropping to ca. $50 \%$ immediately after switching to maize suspensions regardless of whether the suspensions were pre-treated or not.

All profiles exhibited a gradual rise in cumulative output corresponding to the daily feeding of each reactor, with weekends identifiable by temporary plateaux. This was independent of feed type. Only minor differences (up to $10 \%$ after 24 days of starting the experiment) were apparent, which could be attributed to minor variation of the $\mathrm{AD}$ cultures or conditions within the reactor (i.e. the number density of microbes and their physiological state could be different in each reactor). An average maximum biogas production of 101 per day has been observed across all reactors where the reactor had been fed for more than two consecutive days. However, cumulative $\mathrm{CH}_{4}$ volume exhibited a noticeable difference from ca. day 4 onwards and ca. $20 \%$ variation can be seen by day 24 between the sewage sludge fed reactor and the reactor fed with pre-treated, washed maize. This could be due to the digestibility of the feed, or alternatively the washing of samples which had removed soluble and easily digestible substrates (13\% less for plasma treated washed sample, compared to the unwashed maize). For example, maize is $19 \%$ starch (see Table 1), which is an easily digestible component and any unbound starch would be removed during washing. The sewage sludge could also have had a better balance of nutrients, whereas lignocellulosic bio-energy crops (such as maize) are often rich in carbohydrates but low in organic nitrogen, along with micro and macro nutrients required for microbial growth- in continuous, long-term AD (Li et al., 2009). The specific methane yield for raw maize, pre-treated unwashed maize, pre-treated washed maize and sewage sludge in this study are 230.5, 228.9, 196.4, and $2681 \mathrm{CH}_{4} / \mathrm{kg}$ VS respectively, and that confirms our conjecture above. These methane yields are similar to that reported by Menardo et al. (2012) for AD of maize.
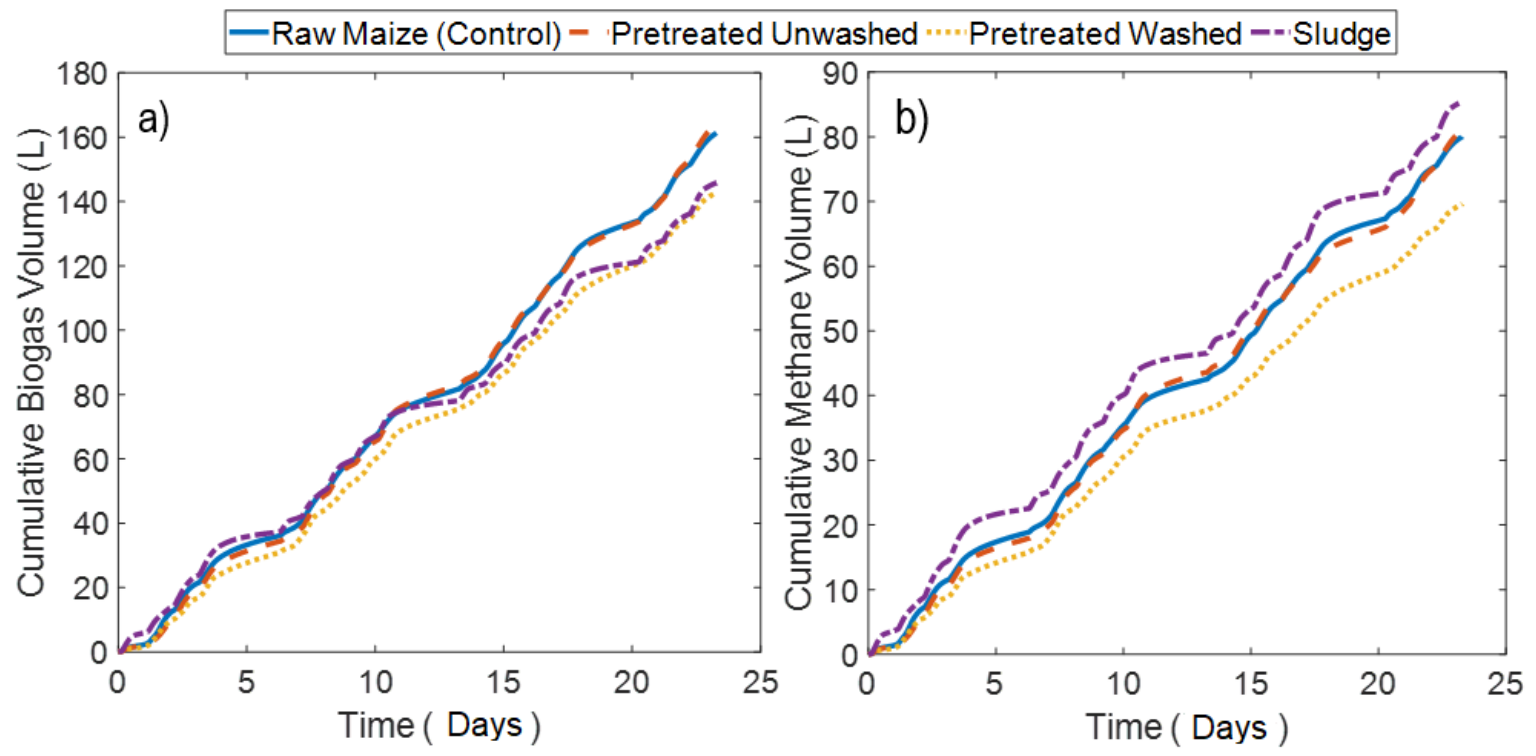

Figure 5. Results of gaseous output from the continuously-fed AD reactor (a) Cumulative biogas volume (b) Cumulative methane volume 


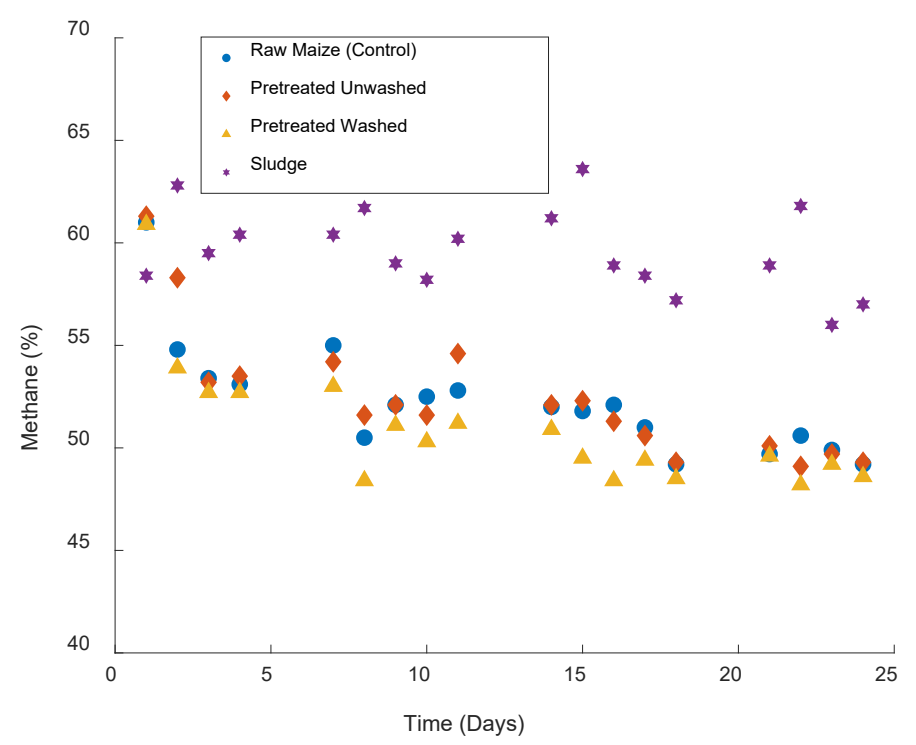

Figure 6. Results of $\mathrm{CH}_{4} \%$ in biogas from the continuously-fed $\mathrm{AD}$ reactors

As the reactors were fed on a daily basis, it is probable that easily digestible material contained in the maize (especially starch) was sufficient to maintain $\mathrm{AD}$ process and the pre-treated lignocellulosic material remained relatively undigested. However, it should be noted that for practical purposes the HRT in this work was maintained at 20 days, which is relatively short for digestion of maize. Longer retention time would possibly benefit further digestion of the unprocessed feed material. It is also possible that the continuous feeding regime could have minimised any toxic shock attributable to plasma-derived inhibitors. Resistance to chemical toxicity has previously been reported for microbial communities subject to progressive exposure, indicating the enrichment of resistant populations which are triggered by the toxicants until equilibrium is reached (Barkay and Pritchard, 1988).

Volatile fatty acids (VFA) are intermediates in the anaerobic biodegradation of maize, leading to ultimately $\mathrm{H}_{2}, \mathrm{CH}_{4}$ and $\mathrm{CO}_{2}$ (Fernández and Sánchez, 2005). The production and degradation of VFA is carried out by two different groups of organisms, in sequence and which are easily destabilised. The determination of VFA concentration is therefore used to assess the impact of pre-treatment on metabolic activities. The start-up of an AD process is usually characterised by variability and instabilities in VFA concentrations, as the balance between hydrolytic, fermentative and methanogenic organisms is established (Hartmann and Ahring, 2005). This can be seen in Figure 7a, where stability is reached after eight days. Thereafter, values of $300-500 \mathrm{mg} / \mathrm{l}$ are in the typical range for a stable digester (Duan et al., 2012). Figure 7d shows that a neutral $\mathrm{pH}$ was also maintained throughout.

For VFA/alkalinity ratio (Ripley's ratio) the following critical values are typically used to determine stability: $<0.4$, digestion system is relatively stable; $0.4-0.8$, a sign of instability; and $>0.8$, significant instability (Callaghan et al., 2002). In all the AD reactors, VFA/alkalinity ratio were detected in the "relatively stable" range (Fig. 7b). Similarly, and as shown in Figure 7c, the $\mathrm{NH}_{4}-\mathrm{N}$ concentration for all reactors, with concentrations ranging between 800 and $1300 \mathrm{mg} / \mathrm{l}$, was outside of the range where inhibitory effects might be expected (Yenigün and Demirel, 2013). The ammonium ion is often the major source of alkalinity in a digester and free ammonia is also a common inhibitor when accelerated hydrolysis of domestic wastes are used. 

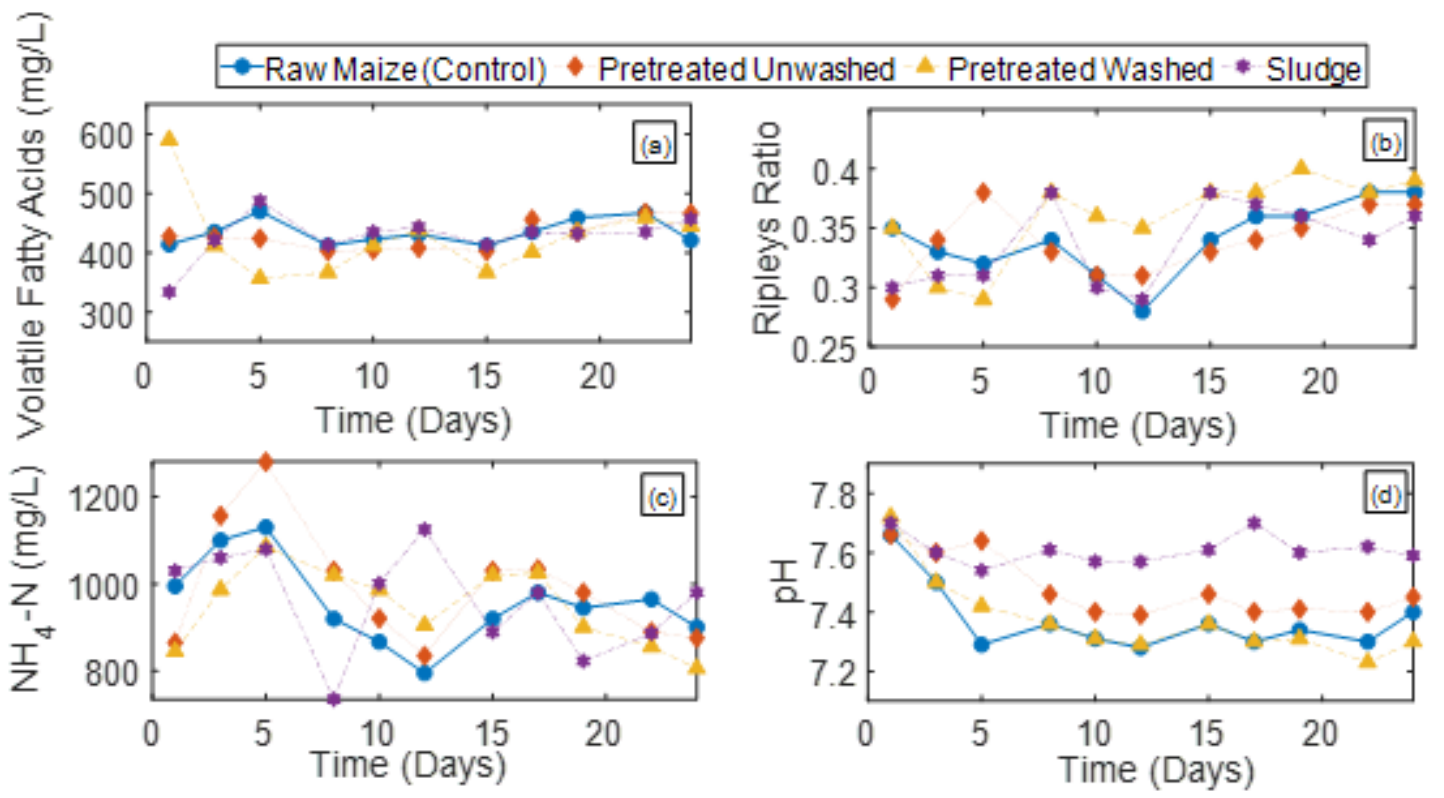

Figure 7. Stability parameters of continuously-fed AD reactors

\subsection{Potential applicability at industrial scale}

Most pre-treatment methods that show promising results at lab/bench-scale are not always suitable for pilot/industrial scale. Scalability, energy consumption, cost of chemicals, operating costs and treatment time are key factors that should be considered when assessing whether a pretreatment technology is suitable for industrial implementation. For this reason, direct comparison of performance of various lignocellulosic pre-treatment methods for anaerobic digestion is not straightforward. Nevertheless, a qualitative analysis of the suitability of the microbubble-plasma pre-treatment is presented here. High mass transfer efficiencies and low-cost mixing achievable with microbubble air-lift loop reactors have been demonstrated at pilot- scale (Zimmerman et al., 2009). The modular system implemented in this approach, i.e. plasma generation inside the plenum chamber, allows large number of treatment sites to be integrated to a single larger pre-treatment vessel and scale-up the operation. The gas-liquid mass transfer efficiency of such reactors can be further enhanced by integrating fluidic oscillator mediated microbubble technology to the plenum chamber (Wright et al., 2019, Rehman et al., 2015).

Each $10^{\circ} \mathrm{C}$ rise in temperature for conventional thermal pre-treatment (assuming $6 \%$ TS feed) would require about $0.2 \mathrm{kWh} . \mathrm{kg}^{-1}$ or ten times more for hydrothermal hydrolysis reported to give a $25-33 \%$ increase in gas yield (Saltea et al., 2013). The total amount of energy attainable from the biogas produced by the three samples (corrected to $20 \mathrm{~g}$ ) was $0.20 \mathrm{kWh}$ (Washed maize), $0.13 \mathrm{kWh}$ (Unwashed maize), and $0.17 \mathrm{kWh}$ (Raw maize). For this energy calculation, the energy value of the biogas was taken as $35.8 \mathrm{~J} \cdot \mathrm{ml}^{-1}$, the percentage of $\mathrm{CH}_{4}$ in the BMP biogas was taken from Table 2 and the total biogas produced was taken from Fig. 4 . The energy consumption for the pre-treatment carried out in this study was estimated to be $1.86 \mathrm{kWh} \cdot \mathrm{kg}^{-1}$ of raw maize; this gave a net maximum process efficiency of $3.5 \leq \eta \leq 5.4$ (excluding energy needed to heat, and losses from the digesters). However, this figure can be significantly improved with scale-up and with the use of customised plasma power sources. The maize concentration in the pre-treatment suspension was kept at $5 \%$ (wt/wt) in this study as in Wright et al., 2018(a), but it can be increased up to $\sim 10 \%$ (wt/wt) while maintaining the effectiveness of treatment and natural mixing. The amount of chemicals used $(\mathrm{NaOH})$ to neutralize the pre-treated suspension before feeding is small compared to pure chemical 
treatments but should also be considered in costing. This novel pre-treatment reactor is primarily designed to generate a range of RONS at the gas-liquid interface and maximize transfer into liquid phase using microbubbles. The $18 \%$ improvement in biogas production observed with the batch AD experiments warrants further studies to improve the efficacy of the reactor, particularly for maize, by varying the cocktail of reactive species produced (optimise feed gas to plasma module and duty cycle, plasma temperature control etc.) and optimising operating parameters (biomass loading to pre-treatment reactor, treatment time and $\mathrm{pH}$ regulation).

\section{Conclusions}

A novel microbubble-enhanced DBD plasma reactor was shown to cause physical and chemical disruption to the structure of maize when treated in tap water. The results for batch AD categorically show that considerable advantage can be obtained by the DBD plasma process using RONS for pretreatment prior to AD. Gas yields were 18\% greater from plasma treated and washed maize in comparison to untreated raw samples. The unwashed samples produced $29 \%$ lower biogas than the untreated samples, potentially suggesting the production of inhibitory by-products. In continuous feeding experiments, there was no noticeable improvement in biogas yields from the plasma pretreatment within the relatively limited hydraulic retention times used in these preliminary tests. There are a number of possibilities for overcoming this apparent lack of improved gas yield, apart from longer retention times, an $\mathrm{AD}$ reactor recycle ratio could be used to dilute fresh inhibitory products entering the $\mathrm{AD}$ process. Further work is required to investigate the balance between hydrolytic, fermentative and methanogenic organisms, of DBD plasma reactor with microbubble treatment, to investigate the scaling up and techno-economic analysis for industrial AD crops. This will enable the clear benefits in biogas yield demonstrated in this study to be transferred to continuous AD processing.

Acknowledgments: This work was funded by grants POC-HD_RD0300C from Plants to Products network of BBSRC NIBB, BB/L013819/1, and British Council Newton Fund (award ref. 216423359). AW also acknowledge the school of ACCME, Loughborough University and EPSRC (EP/M507908/1) for his PhD studentship. Thanks to Micropore Technologies for supplying nickel membranes, and the SEM technical assistance received from Keith Yendall of the Loughborough University Materials and Characterisation Centre. The authors are also grateful to Anthony Eyre and Mark Barron for fabrication of the plasma reactor as well as Graham Moody and Tim Coles for technical assistance.

\section{References}

Abbasi, T.; Tauseef, S.M.; Abbasi, S.A., 2012. A Brief History of Anaerobic Digestion and "Biogas." In Biogas Energy; Springer New York: New York, NY, pp. 11-23.

APHA Standard Methods for the Examination of Water and Wastewater; 1999

Barkay, T.; Pritchard, H., 1988. Adaptation of aquatic microbial communities to pollutant stressto $\mathrm{Hg}^{2+}$ Stress. Microbiol. Sci. 5, 165-169.

Bougrier, C.; Albasi, C.; Delgenès, J.P.; Carrère, H., 2006. Effect of ultrasonic, thermal and ozone pretreatments on waste activated sludge solubilisation and anaerobic biodegradability. Chem. Eng. Process. Process Intensif. 45, 711-718.

Brenner, E.A.; Salazar, A.M.; Zabotina, O.A.; Lübberstedt, T., 2012. Characterization of European forage maize lines for stover composition and associations with polymorphisms within Omethyltransferase genes. Plant Sci. 185-186, 281-287. 
Carlsson, M.; Lagerkvist, A.; Morgan-Sagastume, F., 2012. The effects of substrate pre-treatment on anaerobic digestion systems: A review. Waste Manag. 32, 1634-1650.

Duan, N.; Dong, B.; Wu, B.; Dai, X., 2012. High-solid anaerobic digestion of sewage sludge under mesophilic conditions: Feasibility study. Bioresour. Technol. 104, 150-156.

Eastman, J.A.; Ferguson, J.F., 1981. Solubilization of Particulate Organic Carbon during the Acid Phase of Anaerobic Digestion. J. (Water Pollut. Control Fed. 53, 352-366.

Fernandes, T. V.; Klaasse Bos, G.J.; Zeeman, G.; Sanders, J.P.M.; van Lier, J.B., 2009. Effects of thermochemical pre-treatment on anaerobic biodegradability and hydrolysis of lignocellulosic biomass. Bioresour. Technol. 100, 2575-2579.

Fernández, A.; Sánchez, A.; Font, X., 2005. Anaerobic co-digestion of a simulated organic fraction of municipal solid wastes and fats of animal and vegetable origin. Biochem. Eng. J. 26, 22-28.

García-Cubero, M.T.; González-Benito, G.; Indacoechea, I.; Coca, M.; Bolado, S., 2009. Effect of ozonolysis pretreatment on enzymatic digestibility of wheat and rye straw. Bioresour. Technol. 100, 1608-1613.

García-Rosales, G.; Colín-Cruz, A., 2010. Biosorption of lead by maize (Zea mays) stalk sponge. J. Environ. Manage. 91, 2079-2086.

Hartmann, H.; Ahring, B.K., 2005. Anaerobic digestion of the organic fraction of municipal solid waste: Influence of co-digestion with manure. Water Res. 39, 1543-1552.

Heiske, S.; Schultz-Jensen, N.; Leipold, F.; Ejbye Schmidt., J., 2013. Improving Anaerobic Digestion of Wheat Straw by Plasma-Assisted Pretreatment, J Atom. M. P. 2013

Karimi, K.; Taherzadeh, M.J., 2016. A critical review of analytical methods in pretreatment of lignocelluloses: Composition, imaging, and crystallinity, Bioresour. Technol. 200, 1008-1018

Koyama, M.; Yamamoto, S.; Ishikawa, K.; Ban, S.; Toda, T., 2015. Enhancing anaerobic digestibility of lignin-rich submerged macrophyte using thermochemical pre-treatment. Biochem. Eng. J. 99, 124-130.

Koyama, M.; Yamamoto, S.; Ishikawa, K.; Ban, S.; Toda, T., 2017. Inhibition of anaerobic digestion by dissolved lignin derived from alkaline pre-treatment of an aquatic macrophyte. Chem. Eng. J. 311, 55-62.

Kumar, P.; Barrett, D.M.; Delwiche, M.J.; Stroeve, P., 2009. Methods for Pretreatment of Lignocellulosic Biomass for Efficient Hydrolysis and Biofuel Production. Ind. Eng. Chem. Res. $48,3713-3729$.

Lemeune, S.; Jameel, H.; Chang, H.M.; Kadla, J.F., 2004. Effects of Ozone and Chlorine Dioxide on the Chemical. Properties of Cellulose Fibers. College of Natural Resources, North Carolina State University, Raleigh, North Carolina 27695, DOI 10.1002/app.20509

Li, X.; Li, L.; Zheng, M.; Fu, G.; Lar, J.S., 2009. Anaerobic Co-Digestion of Cattle Manure with Corn Stover Pretreated by Sodium Hydroxide for Efficient Biogas Production. Energy \& Fuels. 23, 4635-4639.

Menardo, S., Airoldi, G., Balsari, P., 2012. The effect of particle size and thermal pre-treatment on the methane yield of four agri-cultural by-products. Bioresour. Technol. 104, 708-714

Moestedt, J.; Malmborg, J.; Nordell, E., 2015. Determination of Methane and Carbon Dioxide Formation Rate Constants for Semi-Continuously Fed Anaerobic Digesters. Energies. 8, 645655.

Negri, M.; Bacenetti, J.; Brambilla, M.; Manfredini, A.; Cantore, A.; Bocchi, S., 2014. Biomethane production from different crop systems of cereals in Northern Italy. Biomass and Bioenergy. 63, 321-329.

Negri, M.; Bacenetti, J.; Manfredini, A.; Lovarelli, D.; Fiala, M.; Tommaso Maria Maggiore; Bocchi, S., 
2014. Evaluation of methane production from maize silage by harvest of different plant portions. Biomass and Bioenergy. 67, 339-346.

O'Connor, R.T.; DuPré, E.F.; McCall, E.R., 1958. Applications of infrared absorption spectroscopy to investigations of cotton and modified cottons: Part 1: Physical and crystalline modifications and oxidation. Textile Res J. 28, 5, 382-392, https://doi.org/10.1177/004051755802800503 Panneerselvam, A.; Sharma-Shivappa, R.R.; Kolar, P.; Ranney, T.; Peretti, S., 2013. Potential of ozonolysis as a pretreatment for energy grasses. Bioresour. Technol. 148, 242-248.

Paulo, L.M.; Stams, A.J.M.; Sousa, D.Z., 2015. Methanogens, sulphate and heavy metals: a complex system. Rev. Environ. Sci. Bio/Technology. 14, 537-553.

Rasi, S.; Veijanen, A.; Rintala, J., 2007. Trace compounds of biogas from different biogas production plants. Energy. 32, 1375-1380.

Raspolli Galletti, A.M.; D’Alessio, A.; Licursi, D.; Antonetti, C.; Valentini, G.; Galia, A.; Nassi O Di Nasso, N., 2015. Midinfrared FT-IR as a tool for monitoring herbaceous biomass composition and its conversion to furfural. J. Spectrosc. 2015.

Rehman, F.; Medley, G.J.D.; Bandulasena, H.; Zimmerman, W.B.J., 2015. Fluidic oscillator-mediated microbubble generation to provide cost effective mass transfer and mixing efficiency to the wastewater treatment plants, Environ. res. 137, 32-39.

Ripley, L.E.; Boyle, W.C.; Converse, J.C., 1986. Improved Alkalimetric Monitoring for Anaerobic Digestion of High-Strength Wastes. Water Pollut. Control Fed. 58, 406-411.

Saetea, P.; Tippayawong, N., 2013. Recovery of Value-Added Products from Hydrothermal Carbonization of Sewage Sludge. ISRN Chem. Eng. 2013, 1-6.

Sluiter, A.; Hames, B.; Ruiz, R.; Scarlata, C.; Sluiter, J.; Templeton, D., 2005. Determination of Ash in Biomass, Technical Report, NREL/TP-510-42622

Sluiter, A.; Hames, B.; Ruiz, R.; Scarlata, C.; Sluiter, J.; Templeton, D.; Crocker, D., 2008. Determination of Structural Carbohydrates and Lignin in Biomass, Technical Report NREL/TP-510-42618

Sluiter, A.; Ruiz, R.; Scarlata, C.; Sluiter, J.; Templeton, D., 2005. Determination of Extractives in Biomass, Technical Report NREL/TP-510-42619

Souza-Correîa, J.A.; Ridenti, M.A.; Oliveira, C.; Araújo, S.R.; Amorim, J., 2013. Decomposition of lignin from sugar cane bagasse during ozonation process monitored by optical and mass spectrometries. J. Phys. Chem. B. 117, 3110-3119.

Strömberg, S.; Nistor, M., Liu, J., 2014. Towards eliminating systematic errors caused by the experimental conditions in Biochemical Methane Potential (BMP) tests. Waste Manage. 34, 1939-1948

Synytsya, A.; Novak, M., 2014. Structural analysis of glucans. Ann. Transl. Med. 2, 1-14.

Travaini, R.; Martín-Juárez, J.; Lorenzo-Hernando, A.; Bolado-Rodríguez, S., 2016. Ozonolysis: An advantageous pretreatment for lignocellulosic biomass revisited. Bioresour. Technol. 199, 212.

Vezzu, G.; Lopez, J.L.; Freilich, A.; Becker, K.H., 2009. Optimization of large-scale ozone generators. IEEE Trans. Plasma Sci. 37, 890-896.

Wright, A.; Bandulasena, H.; Ibenegbu, C.; Leak, D.; Holmes, T.; Zimmerman, W.; Shaw, A.; Iza, F., 2018. Dielectric barrier discharge plasma microbubble reactor for pretreatment of lignocellulosic biomass. AIChE J. 64, 3803-3816.

Wright, A.; Marsh, A.; Ricciotti, F.; Shaw, A.; Iza, F.; Holdich, R.; Bandulasena, H.C.H., 2018. Microbubble-enhanced dielectric barrier discharge pretreatment of micro crystalline cellulose. Biomass and Bioenergy. 118, 46-54

Wright, A.; Taglioli, M.; Montazersadgh, F.; Shaw, A.; Iza, F.; Bandulasena, H.C.H., 2019. 
Microbubble-enhanced DBD plasma reactor: Design, characterisation and modelling. Chem. Eng. Res. Des. 144, 159-173.

Yenigün, O.; Demirel, B., 2013. Ammonia inhibition in anaerobic digestion: A review. Process Biochem. 8, 901-911

Zimmerman, W.B.J.; Hewakandamby, B.N.; Tesař, V.; Bandulasena, H.C.H.; Omotowa, O.A., 2009, On the design and simulation of an airlift loop bioreactor with microbubble generation by fluidic oscillation, Food Bioprod. Process., 87, 215-227. 